This is an electronic reprint of the original article. This reprint may differ from the original in pagination and typographic detail.

Author(s): Huotari, Pertti; Heikinaro-Johansson, Pilvikki; Watt, Anthony; Jaakkola, Timo

Title: $\quad$ Fundamental movement skills in adolescents : secular trends from 2003 to 2010 and associations with physical activity and BMI

Year: $\quad 2018$

Version:

Please cite the original version:

Huotari, P., Heikinaro-Johansson, P., Watt, A., \& Jaakkola, T. (2018). Fundamental movement skills in adolescents : secular trends from 2003 to 2010 and associations with physical activity and BMI. Scandinavian Journal of Medicine and Science in Sports, 28(3), 1121-1129. https://doi.org/10.1111/sms.13028

All material supplied via JYX is protected by copyright and other intellectual property rights, and duplication or sale of all or part of any of the repository collections is not permitted, except that material may be duplicated by you for your research use or educational purposes in electronic or print form. You must obtain permission for any other use. Electronic or print copies may not be offered, whether for sale or otherwise to anyone who is not an authorised user. 
MR PERTTI HUOTARI (Orcid ID : 0000-0002-7263-6871)

Article type : Original Article

\title{
Fundamental movement skills in adolescents: Secular trends from 2003 to 2010 and associations with physical activity and BMI
}

\author{
Huotari Pertti ${ }^{1}$, Heikinaro-Johansson Pilvikki ${ }^{1}$, Watt Anthony ${ }^{2}$ \& Jaakkola Timo ${ }^{1}$ \\ ${ }^{1}$ University of Jyväskylä, Department of Sport Sciences, Finland \\ ${ }^{2}$ College of Arts and Education, Victoria University, Australia.
}

Correspondence: Dr. Pertti Huotari, University of Jyväskylä, Department of Sport Sciences, P.O. Box 35, 40014 University of Jyväskylä, Finland.

Phone: +358408053946, Fax: +358142602101

email : pertti.huotari@jyu.fi

Date of Resubmission: 26.9.2017

\section{Abstract}

The aim of this study was to examine the secular trends in fundamental movement skills (FMS) among 15-16-year-old adolescents at two assessment points scheduled in 2003 and 2010, and to investigate the associations between FMS, physical activity (PA) and body mass index (BMI). In 2003, self-reported PA, weight and height, and objective FMS scores were collected from 2390 students and in 2010, similar data was generated from a second sample of 1346 students. FMS were assessed during both assessment phases using three identical objective FMS tests that were figure 8 
dribbling, jumping laterally, and coordination track tests. This study indicated that the sum index of FMS did not change among the boys and the girls between two data collection points. However, findings demonstrated a secular decline in coordination test scores in both gender groups between two measurement points but an improvement in girls' object control skills between 2003 and 2010. The results also showed that FMS had a significant main effect on BMI in both gender groups, whereas the main effect of PA on BMI was not significant for either gender group. Results also demonstrated that there was no significant interaction effect between FMS and PA on BMI in either of the girls' or the boys' groups.

\section{INTRODUCTION}

The World Health Organization (WHO) has stated that physical activity (PA) is an important factor for people's health and well-being. ${ }^{1}$ However, previous studies in western countries have shown that the majority of adolescents fail to meet current PA recommendations of at least 60 min of daily moderate-to-vigorous PA. ${ }^{2}$ Additionally, it has been reported that overweight and obesity have increased dramatically among youth over the world during last decades. ${ }^{3}$ It is evident that insufficient engagement in PA and increasing overweight and obesity constitute serious risk factors for overall health and well-being among children and adolescents. ${ }^{4}$ Motor skill competency developed during childhood and adolescence has also been identified as one important contributor that supports PA participation and the maintenance of healthy body weight in adulthood. ${ }^{5,6}$

Gallahue and Cleland-Donelly (2007) described fundamental movement skills (FMS) as an organized series of basic movements that involve the combination of 
movement patterns of two or more body parts. The skills are categorized in accordance with stability, locomotor, and object control activities. Stability skills are defined as the process for maintaining postural stability while moving or being in place. Stability skills constitute bending, stretching, twisting, turning, swinging, inverted supports, body rolling, landing/stopping, dodging, and balancing. Locomotor skills include movement patterns such as walking, running, jumping, hopping, galloping, skipping, hopping, sliding, leaping, and climbing. Object control skills involve manipulating or grasping objects and include throwing, catching, bouncing, trapping, kicking, striking, volleying, punting, and ball rolling. ${ }^{7}$ Previous research has indicated that FMS competency is an important antecedent of PA in childhood and adolescence ${ }^{8.10}$ More specifically, previous longitudinal studies have demonstrated positive associations between FMS of children to PA levels demonstrated during adolescence, and between the FMS of adolescents to PA levels of young adults. ${ }^{11,12}$

Although there is evidence showing the association between FMS and later PA engagement, the review of previous literature demonstrates that secular trend studies investigating changes in children and adolescents' motor skills performances over time are scarce. To our knowledge, there are only two secular trend studies that have reported the replicated use of a set of measures to analyze motor skills as the underlying basis for later comparison of PA. Roth et al (2010) investigated secular trends in the motor skills of German 3 to 7 -year old preschool children at the four assessment periods of 1973, 1985, 1989 and 2007. Children in 2007 performed equally or significantly better in standing broad jump and obstacle course tests than the children tested in 1973 and 1989 but, the scores in balancing backwards and target throwing declined from 1985 to $2007 \cdot{ }^{13} \mathrm{Hardy}$ et al (2013) analyzed the FMS competencies of 9-15 years-old Australian children and adolescents among cross- 
sectional samples collected at 1997, 2004, and 2010. In general, children and adolescents' competencies improved from 1997 to 2004 in both gender groups. Largest improvements were observed in the sprint run, vertical jump and catch. Additionally, both gender groups improved in catching skills, but only girls improved in kicking skills from 2004 to 2010 . However, competency in the vertical jump skill significantly decreased from 2004 to $2010 .^{14}$

It has been proposed that FMS, PA and BMI are related variables within child and adolescent populations. ${ }^{4,10,15,16}$ A developmental perspective on the role of motor skill competence in PA presented by Stodden et al (2008) is a widely utilized framework to explain these relationships. In this conceptual model Stodden et al (2008) highlight that there is a dynamic and reciprocal relationship between obesity, PA, motor skill competency, perceived motor competence and physical fitness. Additionally, Stodden et al (2008) suggest that there is a positive spiral of engagement from high motor skill competence through higher perceptions of motor skill competence, greater engagement in PA, and higher levels of health-related physical fitness to healthy weight status.

Empirical studies have demonstrated that FMS, PA and BMl are shown to be significantly correlated based on assessments undertaken during childhood and adolescence ${ }^{15-17}$ More specifically, research has indicated a negative relationship between FMS and being overweight, ${ }^{16,17}$ and a positive relationship between FMS and a healthy weight status within child and adolescent cohorts. ${ }^{15}$ Physical activity, motor competency and cardiorespiratory fitness collectively have also been shown to have a strong longitudinal impact on the body fat levels of children. ${ }^{18}$ Additionally, there is evidence that physical inactivity correlates positively with obesity, ${ }^{4,19}$ and FMS with 
moderate or vigorous levels of PA. ${ }^{16}$ It should also be noted that the majority of previous studies investigating the associations between motor skills, BMI and PA have been conducted using samples involving children younger than 12 years., 10, 20,21

The purpose of this study is twofold. Firstly, we aim to examine secular trends in the FMS patterns of national samples of Finnish adolescents collected at two assessment points in 2003 and 2010. In this research phase, we control for the effects of BMI and leisure-time PA engagement. Secondly, we investigate associations between FMS, leisure-time PA and BMI within the combined sample..$^{10,16,}$

${ }^{17}$ More specifically, we investigate if there is an interaction effect between leisuretime PA engagement and FMS on BMI. All analyses of this study will be done separately for both gender groups.

\section{METHODS}

\subsection{Study design and participants}

This study is based on data collected during the national evaluation of learning outcomes of physical education students in their final (ninth) year of junior high school undertaken during 2003 and 2010. Data collection was commissioned by the National Board of Education of Finland, and commissioned within the legislative framework to conduct these evaluations as an element to assess curriculum learning outcomes. These evaluations and data collection procedures were similar in both cohorts.

In this study the samples were recruited using a three-phased stratified random-sampling procedure and drawn from schools representing different provinces and types of municipalities (cities, urban and rural). In the first phase, the municipalities were selected from different geographical areas of Finland. In the second phase, the random sample of the schools matched for the municipality size 
was collected. In third phase, the students were randomly selected from the alphabetized list. All students were selected from schools that had 1-30 ninth graders, 30 participants were selected from schools that had 31-99 students at ninth grade, 36 participants were selected from schools that had 100-150 students at ninth grade and 40 participants were selected from schools that had more than 151 students at ninth grade.

In 2003, the data were collected from 100 Finnish-speaking and 11 Swedishspeaking comprehensive schools, and following the sampling procedure a PA selfreport questionnaire, FMS tests were completed by 2390 students (1207 boys and 1183 girls). In 2010, the data were collected from 47 Finnish speaking and 4 Swedish-speaking comprehensive schools and following sampling, the PA self-report questionnaire and FMS tests were completed by 1346 students (683 boys and 663 girls) (table 1).

Fewer schools were included in evaluation study 2010 than 2003 because national evaluations of other school subjects were being conducted at the same time, and the Finnish Ministry of Culture and Education determined that schools had to participate in only one evaluation study at the same time. However, schools and the students of the 2010 cohort represented the different provinces and types of municipalities of Finland adequately based on the distribution comparison of that sample to the distribution of all schools and all ninth graders in Finland

All data were obtained from the schools by physical education teachers who received exact instructions of the test arrangements from researchers. Researchers confirmed that teachers had understood all instructions related to physical tests to be conducted. Additionally, all of those teachers have a Master's degree in sport pedagogy which was considered to be an indication of their expertise in all areas of 
physical education including testing of motor performance. All self-report data was collected using a questionnaire format completed in a quiet classroom. Students could refrain from participating tests because of illness or injury. The tests were part of the mandatory PE curriculum and the non-participation rate due to disease or injury was $<5 \%$ at both cohorts in 2003 and 2010 .

The analyses completed within the second research aim used a final combined sample that included all 15 to 16 -year old students from both the 2003 and 2010 cohorts, who participated in all three FMS tests and reported their height and weight and leisure time PA on a questionnaire. Identical FMS were assessed at both data collection points.

\subsection{Measurements}

\subsubsection{Objective measurements of FMS}

Figure 8 test. Students' object control skills were measured by the figure 8 test in which the task involves dribbling a volleyball around a figure-8 shaped track, first using the feet ( $30 \mathrm{sec}$.), and second using the hands ( $30 \mathrm{sec}$.). The objective was to complete the course as many times as possible during a 1-min interval, and the number of half-a-loops completed was used as the outcome score. Previous research reported test-retest correlations of 0.70 for boys and 0.60 for girls. ${ }^{22}$

Lateral jumping test. Dynamic balance, quickness and explosive strength of lower limbs was measured by a two-legged jumping test in which a child performs 15 seconds of consecutive jumps from one side to another with their legs in a parallel position. These jumps are performed over a small wooden beam $(60 \mathrm{~cm} \times 4 \mathrm{~cm} \times 2$ $\mathrm{cm})$. The number of jumps during $15 \mathrm{~s}$ was used as the outcome. ${ }^{23}$

Motor coordination track test. A combination of various types of FMS including locomotor (running, jumping) and stability skills (rolling, turning, dodging, landing) 
were measured by the motor coordination track test. ${ }^{24}$ The test was performed along $12 \mathrm{~m}$ course and consists of the following movement sequences; starting position with feet together, forward run $5 \mathrm{~m}$, forward roll on a mat, forward run $5 \mathrm{~m}$, jump over wooden gymnastic bench with $180^{\circ}$ turn, stop, jump over the wooden gymnastic bench, forward run $5 \mathrm{~m}$, lay down facing the mat hands next to torso, forward run $5 \mathrm{~m}$ to the finish line. The time to cover the course was used as the outcome.

Students had two attempts in lateral jumping and coordination track tests and in both tests the higher score was used. In the figure 8 test students had a single 1minute attempt, and if students made an error during performance (e.g., they lost the control to the ball), the stopwatch was not stopped. They were required to pick up the ball and continue their performance.

The results from the three FMS tests were used to construct a genderstratified FMS index, which was formed by summing the age-adjusted z-scores for the figure 8 test, lateral jumping test and motor coordination track test. The Cronbach's alpha for this index was 0.75 in boys and 0.78 in girls in 2003 and 0.73 and 0.80 respectively in 2010. In statistical analyses regarding the second research task, the FMS sum variable was recoded into tertiles representing students who have low, average and high FMS. The range of z-scores for low FMS group were $11.70--0.86$ for boys and $-10.57--0.80$ for girls, for the average FMS group -0.85 -1.18 for boys and $-0.79-1.04$ for girls, and for the high FMS group $1.19-6.90$ for boys and $1.05-6.96$ for girls. 


\subsubsection{Assessment of BMI}

Participants individually reported their estimated weight and height on a questionnaire in a classroom, and the estimation of standard BMI was later calculated. Previous research conducted with same study population showed that the mean of the estimated BMI increased slightly in boys and remained approximately on the same level in girls between assessments (Palomäki et al., 2015).

\subsubsection{Assessment of PA}

Participants' PA was measured by a leisure time PA questionnaire (Nupponen et al., 2010). The questionnaire independently considers organized and unorganized PA and it includes two questions for each type of activity; 1) frequency of PA bouts with durations of at least 20 min, and 2) duration (h) of vigorous PA, defined as activity leading to sweating and heavy breathing. The questionnaire items included seven response options for frequency of PA and six response options for duration of vigorous PA. Both items were re-coded into a five category classification framework. The classification for PA was made by a combination of frequency of PA and duration of vigorous PA and participants received a one value (1-5) for both organized and unorganized PA. The PA index was computed as mean of these two values. The same type of PA index has been utilized also in previous research concerning cardiovascular performance within normal and overweight adolescents. ${ }^{25}$

For the second research task of this study PA index was recoded into tertiles representing students to have low, average or high PA index.

The reliability of the leisure-time PA questionnaire has also been found to be satisfactory in previous studies. More specifically, Nupponen et al (2010) reported test-retest correlations of the questionnaire to be satisfactory. Their study reported 
correlation coefficients in the sub-samples $(n=1850)$ pooled over the years of 0.80 for frequency of organized PA and 0.66 for frequency of unorganized PA ${ }^{26}$ In the current study, internal consistency of PA items was satisfactory (i.e., Cronbach's alpha of 0.80$)$.

\subsection{Statistical analyses}

Descriptive analyses were conducted to determine means and standard deviations of study variables. Additionally, Spearman's correlation coefficients were used to investigate associations among FMS items, PA and BMI. To adjust for the potential modifying effects of province (i.e., south, west, east, middle and north) and the type of municipality (i.e., urban, rural and densely populated community), the complex samples general linear model (GLM) method with $95 \%$ confidence intervals (95\% Cl) was used to compare differences in FMS performances between data sets collected at 2003 and 2010. BMI and PA were used as covariates in these analyses. Additionally, Cohen's $d$ effect-sizes for differences between data sets collected at 2003 and 2010 were computed (Cohen, 1988). The threshold values for the effectsize were; 0.10 (small), 0.30 (medium) and 0.50 (large). ${ }^{27}$

The interaction and main effects of FMS and PA engagement towards BMI were analyzed by the complex samples GLM method. For this analysis we combined 2003 and 2010 data cohorts into one data set. All statistical analyses were conducted separately for the girls and the boys and were performed by SPSS statistical software, version 22.0.

\section{RESULTS}

Table 2 shows changes in secular trends in FMS between 2003 and 2010.The results of GLM indicate that the FMS sum index remained stable in the boys and in the girls groups between the two data collection points. Results also demonstrate 
that scores of the coordination track decreased slightly in both gender groups between 2003 and 2010. Additionally, scores for the figure 8 test increased slightly among girls but not in the boys' group between the two data collection points. Results also showed that there were no significant changes in the lateral jumping test scores in either gender group between 2003 and 2010.

Table 3 indicates that relationships among study variables were similar in both data sets collected at 2003 and 2010. Correlation results revealed small to moderate associations among study variables in both gender groups. Generally, correlation coefficients among variables were higher for the boys compared with the girls. Most of the FMS variables had a stronger correlations with PA in the boys' group than in the girls' group. Additionally, the BMI had negligible associations with PA index in both gender groups.

The GLM revealed that the sum index of FMS had significant main effect on $\mathrm{BMI}$ in the girls' $(F=33.12, p<0.001)$ and in the boys' groups $(F=44.87, p<0.001)$ (table 4). The full model explained $4.7 \%$ of variance of BMI for both the boys and the girls. Results also demonstrated that the main effect of PA on BMI was not statistically significant in the boys' $(F=1.02, p=0.389)$ or in the girls' group $(F=$ $0.19, p=0.831)$. Additionally, there was no significant interaction effects between the sum index of FMS and PA engagement on BMI in the boys' group $(F=0.40, p=$ $0.804)$ or in the girls' group $(F=1.46, p=0.279)$.

\section{DISCUSSION}

Aims of this study were to analyze secular trends in FMS within Finnish adolescent samples aged 15-16 years-old at two distinct chronological assessment points of 2003 and 2010, and to examine associations between FMS, PA engagement and BMI. The results showed that the FMS sum index remained stable for the boys and 
the girls between 2003 and 2010. Findings also demonstrated a secular decline in coordination test scores of both gender groups between the two measurement points. However, girls' object control skills significantly improved between 2003 and 2010. The results also showed that FMS sum index has significant main effect on $\mathrm{BMI}$ in both gender groups, whereas the main effect of PA on BMI was not significant for either gender group. The results also demonstrated that there was no interaction effect between FMS sum index and PA on BMI either in the girls' or in the boys' group.

Comparison of results from the current study with previous investigations highlight that FMS scores among Finnish adolescents have decreased similarly to the FMS scores of Australian adolescents samples. ${ }^{14}$ Specifically, Hardy et al. (2013) found improvements in almost all measured FMS within Australian adolescents between 1997 and $2010 .{ }^{14}$ A possible reason for the differences between results could be that the Finnish sample included students older than those in the Hardy et al (2013) study. ${ }^{14}$ Earlier studies have also demonstrated that PA decreases consistently occur at junior high school level when adolescents are between the ages of 12 to 16 years-old., ${ }^{2,2}$ The decrease in PA engagement during puberty may limit the normal development of FMS across the period of adolescence.

It is important to note that the scores on the coordination track test decreased for both gender groups from 2003 to 2010 . The coordination track test includes simple locomotor skills such as running and jumping, and stability skills such as balancing. Results of the coordination track test indicated that Finnish adolescents in 2010 are demonstrating lower levels of competence on simple motor tasks than observed in earlier 2003 data collection. This changing pattern causes concern because FMS are important to support adolescents' participation in the physical 
activities associated with exercise, sport and their daily lives. ${ }^{7}$ Previous researchers have consistently reinforced that FMS are important antecedents of PA engagement in childhood and adolescence. ${ }^{8-10}$

An interesting finding was that girls improved in object control skills scores from 2003 to 2010 . The object control skill test used in this study analyzed ball dribbling involving both the hands and feet, which are specific skills related to sports such as basketball and soccer. A possible explanation for this change in FMS may be that ball games such as soccer, basketball and floorball have increased in popularity within the female population. ${ }^{29}$ This social trend has been recognized in previous Finnish large scale sport club and physical education investigations. ${ }^{29,30}$

The results of this study support previous findings regarding association patterns between FMS abilities and BMI. ${ }^{15-18}$ Current findings are also aligned with the developmental perspective regarding the role of motor skill competence in PA presented by Stodden et al (2008), whereby FMS are associated with BMI in adolescence. ${ }^{5}$ In our data, students who had low FMS had significantly higher BMI comparing with the students who had average or high FMS. This finding reinforces the association between FMS and BMI. Physical education may serve a critical role in improving adolescents' FMS and PA because it is positioned as a societal agent that can reach the entire age cohort of youth. ${ }^{31}$ Therefore, it is important that all physical education curriculums continue to emphasize both the learning and practicing of FMS. Particular attention should be directed toward the students who have low FMS. 
The strengths of this study were nationally samples with relatively large numbers of participants. Additionally, this study used objective measurements of FMS that were identical within the two data collection phases, thus facilitating the capability to compare results of cohorts collected in 2003 and 2010.

In the current study, limitations were present in regards to self- reported assessment of participants' weight, height and PA. The results of the study were also limited due to a lack of data regarding the test-retest reliability of the assessments, particularly in relation to the teachers' ability to carry out the objective measurements. Although Berner et al (2003) showed that self-reported height and weight correlated highly with objective values, it is still possible that 15-16-year-old students overestimate their height and underestimate their weight. ${ }^{32}$ Sherry et al (2007) suggested that compared with normal weight adolescents, overweight adolescents may underestimate their weight but, alternatively, Strauss (1999) reported that over $90 \%$ of adolescents were reasonably reliable when reporting their weight irrespective of being classified as normal weight or overweight. ${ }^{33,34}$ The recording of age in years only, limited the specificity of the analyses of BMI in relation to height and weight, without accounting for gender and exact age of participants in years and months. ${ }^{35,36}$ However, the adoption of a more sophisticated method to investigate adolescents' weight status would warrant the measurement of body fat mass by bioelectrical impedance equipment. Additionally, self-report and objective measurements of PA have been shown to have specific advantages. Objective PA monitoring tends to have higher stability and involve a smaller measurement error than self-report methods. Correspondingly, the self-report method may successfully capture seasonal variation and the impact of participation in a variety of physical activities. ${ }^{37}$ 
The current secular trend data can be effectively generalized to the population of Finnish adolescents. However, it would be speculative to propose that consistent results would be obtained using similar tests with a matched age population in the other countries, as such, further studies regarding FMS would be needed. Future studies could also extend data collection frameworks by utilizing newer objective methods, such as accelerometers or recent pedometer technologies. Investigations should subsequently be conducted to implement interventions to develop FMS especially within groups of high BMI adolescents to ascertain if a specific focus on the knowledge and competence of FMS promotes greater PA engagement within youth and young adults.

\section{Perspectives}

This study identified only small secular changes in FMS task scores whereby it appears that across time adolescents are demonstrating less competence in the performance of some simple motor tasks. The present study purports that FMS are important motor abilities that demonstrate interesting associations with BMI in adolescent samples. However, the association between PA and BMI was not found to be significant. The adoption of a sedentary lifestyle is an increasing pattern of behavior among children and adolescents over the world. The long term impact of this trend may be demonstrated by a negative effect on the performance levels of FMS and development of unhealthy weight status. The ongoing sustainability of both adequate levels of FMS and a heathy weight status may require that greater attention is directed toward a continued school based focus on the development of FMS across both child and adolescent population groups. 


\section{Acknowledgements}

The data collection of this study was funded by the Finnish Ministry of Culture and

Education. We express our warm thanks to the researchers Tuulamarja Huisman, Sanna Palomäki and Jari Metsämuuronen who had important role in data collection in year 2003 and 2010. The funding source had no role in this paper.

\section{Conflicts of interests}

None declared

\section{References}

1. World Health Organization. Global recommendations on physical activity for health. Geneva: WHO; 2010. 58 p.

2. Currie C, Zanotti C, Morgan A, Currie D, de Looze M, Roberts C,... Barnekow V. (Eds.). Social determinants of health and well-being among young people. Health behavior in School-aged Children (HBSC) study: international report from the 2009/2010 survey 2012. Copenhagen: WHO Regional Office for Europe; 2012. (Health Policy for Children and Adolescents, No. 6).

3. Lobstein T, Jackson-Leach R, Moodie ML, Hall KD, Gortmaker SL, Swinburn BA, James WPT, Wang Y, McPherson K. Child and adolescent obesity: Part of a bigger picture. Lancet 2015; 385: 2510-20.

4. Hills AP, Andersen LB, Byrne NM. Physical activity and obesity in children. $\mathrm{Br} \mathrm{J}$ Sports Med 2011; 45: 866-870.

5. Stodden DF, Goodway JD, Langendorfer SJ, Roberton MA, Rudisill ME, Garcia C, Garcia L. A developmental perspective on the role of physical competence in physical activity: An emergent relationship. Quest 2008; 60: 290-306. 
6. Lubans DR, Morgan P, Cliff DP, Barnett LM, Okely AD. Fundamental movement skills in children and adolescents: Review of Associated Health Benefits. Sports Med 2010; 40: 1019-1035.

7. Gallahue D, Cleland-Donnelly F. Developmental physical education for all children. Champaign: Human Kinetics; 2007. 744 p.

8. Okely AD, Booth ML, Patterson JW. Relationship of physical activity to fundamental movement skills among adolescents. Med Sci Sports Exerc 2001; 33(11): 1899-1904.

9. Fisher A, Reilly JJ, Kelly LA, Montgomery C, Williamson A, Paton JY, Grant S. Fundamental movement skills and habitual physical activity in young children. Med Sci Sports Exerc 2005; 37: 684-688.

10. Lopes VP, Rodriques LP, Maia JAR, Malina RM. Motor coordination as predictor of physical activity in childhood. Scand J Med Sci Sports 2011; 21: 663-669.

11. Barnett LM, vanBeurden E, Morgan PJ, Beard R. Perceived sports competence mediates the relationship between childhood motor proficiency and adolescent physical activity and fitness. A longitudinal assessment. Int $\mathrm{J}$ Behav Nutr Phys Act 2008; 5: 40.

12. Jaakkola T, Yli-Piipari S, Huotari P, Watt A, Liukkonen J. Fundamental movement skills and physical fitness as predictors of physical activity: A 6year follow-up study. Scand J Med Sci Sports 2016; 26: 74-81.

13. Roth K, Ruf K, Obinger M, Mauer S, Ahnert J, Schneider W, Graf C, Hebestreit $\mathrm{H}$. Is there a secular decline in motor skills in preschool children? Scand $\mathrm{J}$ Med Sci Sports 2010; 20: 670-678. 
14. Hardy LL, Barnett L, Espinel P, Okely AD. Thirteen-year trends in child and adolescent fundamental movement skills: 1997-2010. Med Sci Sports Exerc 2013; 45: 1965-1970.

15. Bryant ES, James RS, Birch SL, Duncan M. Prediction of habitual physical activity level and weight status from fundamental movement skill level. J Sport Sci 2014; 32: 1775-1782.

16. Barnett LM, Lai SK, Veldman SLC, Hardy LL, Cliff DP, Morgan PJ, Zask A, Lubans DR, Shultz SP, Ridgers ND, Rush E, Brown HL, Okely AD. Correlates of gross motor competence in children and adolescents: A systematic review and meta-analysis. Sports Med 2016; 46: 1663-88.

17. Lopes VP, Stodden DF, Bianchi MM, Maia JAR, Rodriques LP. Correlation between BMI and motor coordination in children. J Sci Med Sport 2012; 15: $38-43$.

18. Lima RA, Pfeiffer KA, Bugge A, Møller NC, Andersen LB, Stodden DF. Motor competence and cardiorespiratory fitness have greater influence on body fatness than physical activity across time. Scand J Med Sci Sports 2017; 00:1-10. https://doi.org/10.1111/sms.12850

19. Anderson PM, Butcher KL. Childhood obesity: trends and potential causes. Future Child 2006; 16: 19-45.

20. Wrotniak BH, Epstein LH, Dorn JM, Jones KE, Kondilis VA. The relationship between motor proficiency and physical activity in children. Pediatrics 2006; 118: e1758-1765.

21. D'Hondt E, Deforce B, Gutier I, De Bourdeaudhuij I, Vayens R, Lenoir MA longitudinal analysis of gross motor coordination in overweight and obese children versus normal-weight peers. Int J Obes 2013; 37(1): 61-67. 
22. Nupponen H. Motor development of 9-16 year olds. (In Finnish: 9-16 vuotiaiden liikunnnallinen kehittyminen). Research Reports on Sport and Health 106. Jyväskylä: LIKES Research Institute; 1997. 258p.

23. Kiphard EJ, Schilling F. Körperkoordinationstest für Kinder 2, überarbeitete und ergänzte Aufgabe. Beltz test, Weinham; 2007.

24. Haag H, Haag G. From physical fitness to motor competence. Aims-contentmethods-evaluation. Frankfurt: Lang; 2001.

25. Palomäki S, Heikinaro-Johansson P, Huotari P. Cardiorespiratory performance and physical activity in normal weight and overweight Finnish adolescents from 2003 to 2010. J Sports Sci 2015; 33: 588-596.

26. Nupponen H, Laakso L, Rimpelä A, Pere L, Telama R. Questionnaire-assessed moderate to vigorous physical activity of the Finnish youth in 1979-2005. Scand J Med Sci Sports 2010; 20: 20-26.

27. Cohen J. Statistical power analysis for the behavioural sciences $\left(2^{\text {nd }} \mathrm{ed}\right.$.). Hillsdale: Erlbaum; 1988.

28. Nader PR, Bradley RH, Houts RM, McRitchie SL, O'Brien M. Moderate-tovigorous physical activity from ages 9 to 15 years. JAMA 2008; 300: 295-305.

29. National Sport Reseach in Finland. Research 2009-2010. Children and adolescents. SLU publications 7/2010.

30. Palomäki S, Heikinaro-Johansson P. Liikunnan oppimistulosten seurantaarviointi perusopetuksessa 2010. (Follow-up evaluation of physical education learning outcomes 2010) Finnish National Board of Education; 2011. 130p.

31. McKenzie TL, Lounsberg MA. Physical education teacher effectiveness in a public health context. Res Q Exerc Sport 2013; 84: 419-430. 
32. Berner ND, Mcmanus T, Galuska DA, Lowry R, Wechsler H. Reliability and validity of self-reported height and weight among high school students. J Adolescent Health 2003; 32: 281-287.

33. Sherry B, Jefferds ME, Grummer-Strawn LM. Accuracy of adolescents self-report of height and weight in assessing overweight status: a literature review. Arch Pediatr Adolesc Med 2007; 161: 1154-61.

34. Strauss R. Comparison of measured and self-reported weight and height in cross-sectional sample of young adolescents. Int J Obes 1999; 23: 904-908.

35. Centers for Disease Control and Prevention. CDC Growth Charts for United States: Methods and Development 2000. Retrieved from

\section{http://www.cdc.gov/growthcharts.}

36. Cole, T.J., Bellizzi, M.C., Flegal, K.M., \& Dietz, W.H. Establishing a standard definition for child overweight and obesity worldwide: international survey. BMJ 2000; 320: 1240-1243.

37. Telama R. Tracking of physical activity from childhood to adulthood: A review. Obesity Facts 2009; 3: 187-195. 
Table 1. Demographic with $95 \% \mathrm{Cl}: \mathrm{s}$, physical and physical activity characteristics of the samples.

\begin{tabular}{|c|c|c|c|c|}
\hline \multirow[b]{2}{*}{ Characteristic } & \multicolumn{4}{|c|}{ Mean $(S D)$} \\
\hline & $\begin{array}{l}\text { Boys } 2003 \\
(n=1167)\end{array}$ & $\begin{array}{l}\text { Boys } 2010 \\
(n=656)\end{array}$ & $\begin{array}{l}\text { Girls } 2003 \\
(n=1181)\end{array}$ & $\begin{array}{c}\text { Girls } 2010 \\
(n=634)\end{array}$ \\
\hline \multirow[t]{2}{*}{ Age (years) } & $15.2(0.4)$ & $15.3(0.4)$ & $15.1(0.3)$ & $15.2(0.4)$ \\
\hline & $15.2: 15.2$ & 15.2:15.3 & $15.1: 15.2$ & 15.2:15.3 \\
\hline \multirow[t]{2}{*}{ Height (cm) } & $174.3(7.0)$ & $175.7(7.7)$ & $164.4(5.9)$ & $165.3(6.3)$ \\
\hline & 173.9:174.7 & 175.1:176.3 & 164.0:164.7 & $164.7: 165.6$ \\
\hline \multirow[t]{2}{*}{ Weight (kg) } & $64.2(10.8)$ & $66.9(12.3)$ & $56.2(8.8)$ & $57.2(9.9)$ \\
\hline & $63.5: 64.8$ & $65.7: 67.5$ & $55.7: 56.7$ & $56.2: 57.6$ \\
\hline \multirow[t]{2}{*}{ BMI } & $23.0(2.9)$ & 23.7 (3.8) & $22.6(2.9)$ & 22.7 (3.1) \\
\hline & 22.9:23.1 & 23.3:23.8 & 22.5:22.7 & 22.5:22.9 \\
\hline $\begin{array}{l}\text { Physical activity (PA) index } \\
\text { Participation in organized sport } \\
(\%)\end{array}$ & $3.0(1.2)$ & $3.1(1.2)$ & $2.7(1.1)$ & $3.0(1.1)$ \\
\hline inactive & 30.8 & 34.3 & 38.7 & 36.7 \\
\hline light active & 8.5 & 8.5 & 13.9 & 14.2 \\
\hline moderately active & 12.5 & 10.9 & 12.2 & 10.9 \\
\hline active & 21.6 & 20.2 & 22.1 & 20.6 \\
\hline very active & 26.6 & 26.0 & 13.2 & 17.6 \\
\hline $\begin{array}{l}\text { Participation in unorganized } \\
\text { sport (\%) }\end{array}$ & & & & \\
\hline inactive & 19.9 & 16.2 & 18.0 & 11.8 \\
\hline light active & 15.4 & 12.0 & 18.9 & 17.3 \\
\hline moderately active & 22.2 & 24.2 & 28.4 & 26.5 \\
\hline active & 24.4 & 21.7 & 18.2 & 21.2 \\
\hline very active & 18.1 & 25.9 & 16.5 & 23.2 \\
\hline
\end{tabular}


Table 2. Means with $95 \% \mathrm{Cl}: \mathrm{s}$, standard deviations, $p$-values and effect-sizes (ES) for BMI and PA- adjusted FMS differences between 2003 and 2010.

\begin{tabular}{|c|c|c|c|c|c|c|}
\hline \multirow[t]{2}{*}{ FMS test item } & \multicolumn{2}{|c|}{ Boys } & \multirow{2}{*}{$\begin{array}{c}95 \% C l \\
p \text {-value } \\
(E S)\end{array}$} & \multicolumn{2}{|c|}{ Girls } & \multirow{2}{*}{$\begin{array}{c}95 \% C l \\
p \text {-value } \\
(E S)\end{array}$} \\
\hline & $\begin{array}{c}2003 \\
n=1167\end{array}$ & $\begin{array}{c}2010 \\
n=656\end{array}$ & & $\begin{array}{c}2003 \\
n=1181\end{array}$ & $\begin{array}{c}2010 \\
n=634\end{array}$ & \\
\hline FMS index & $\begin{array}{c}0.1(2.2) \\
0.0: 0.3\end{array}$ & $\begin{array}{l}-0.2(2.5) \\
-0.4: 0.0\end{array}$ & $\begin{array}{l}0.1: 0.5 \\
p=n s .\end{array}$ & $\begin{array}{l}0.0(2.2) \\
-0.2: 0.1\end{array}$ & $\begin{array}{l}0.1(2.4) \\
-0.1: 0.3\end{array}$ & $\begin{array}{c}0.36: 0.07 \\
p=n s .\end{array}$ \\
\hline $\begin{array}{l}15 \text { s lateral } \\
\text { jump } \\
\text { (repetitions) }\end{array}$ & $\begin{array}{l}44.5(7.8) \\
44.0: 45.0\end{array}$ & $\begin{array}{l}43.9(8.3) \\
43.4: 44.7\end{array}$ & $\begin{array}{c}-0.2: 1.3 \\
p=\mathrm{ns} .\end{array}$ & $\begin{array}{l}44.7(8.1) \\
44.3: 45.2\end{array}$ & $\begin{array}{l}44.9(8.2) \\
44.6: 45.9\end{array}$ & $\begin{array}{c}-1.0: 0.6 \\
p=n s .\end{array}$ \\
\hline $\begin{array}{l}\text { Figure } 8 \text { test } \\
\text { (rounds) }\end{array}$ & $\begin{array}{l}17.0(3.7) \\
16.8: 17.2\end{array}$ & $\begin{array}{l}17.0(3.9) \\
16.8: 17.4\end{array}$ & $\begin{array}{c}-0.4: 0.3 \\
p=n s .\end{array}$ & $\begin{array}{l}13.4(3.0) \\
13.3: 13.6\end{array}$ & $\begin{array}{l}14.1(3.3) \\
13.9: 14.4\end{array}$ & $\begin{array}{c}0.4: 1.0 \\
p=0.021 \\
0.11(E S)\end{array}$ \\
\hline $\begin{array}{l}\text { Coordination } \\
\text { track (s) }\end{array}$ & $\begin{array}{c}9.5(1.4) \\
9.4: 9.6\end{array}$ & $\begin{array}{c}10.0(1.9) \\
9.8: 10.1\end{array}$ & $\begin{array}{c}0.3: 0.6 \\
p=0.005 \\
0.15(E S)\end{array}$ & $\begin{array}{l}10.9(1.6) \\
10.8: 11.0\end{array}$ & $\begin{array}{l}11.2(2.2) \\
11.0: 11.4\end{array}$ & $\begin{array}{c}0.1: 0.5 \\
p=0.024 \\
0.08(E S)\end{array}$ \\
\hline
\end{tabular}

Nonsignificant $p$-values have been presented $p=n s$. 
Table 3. Spearman correlation coefficients between fundamental movement skills (FMS) test scores, body mass index (BMI), Physical activity (PA) index and participation in organized and unorganized physical activity.

\begin{tabular}{|c|c|c|c|c|c|c|c|c|c|}
\hline PA index & $\begin{array}{l}2003 \\
2010\end{array}$ & $\begin{array}{l}0.82^{* \star *} \\
0.82^{\star * *}\end{array}$ & $\begin{array}{l}0.73^{\star \star \star} \\
0.74^{\star \star \star}\end{array}$ & $\begin{array}{l}0.33^{\star \star *} \\
0.30^{\star \star \star}\end{array}$ & $\begin{array}{l}0.30^{\star \star *} \\
0.34^{\star * *}\end{array}$ & $\begin{array}{l}0.40^{\star \star *} \\
0.42^{\star * *}\end{array}$ & $\begin{array}{l}0.03 \\
0.05\end{array}$ & $\begin{array}{l}0.42^{\star \star *} \\
0.42^{\star * *}\end{array}$ & \\
\hline FMS index & $\begin{array}{l}2003 \\
2010\end{array}$ & $\begin{array}{l}0.42^{\star \star *} \\
0.45^{\star * *}\end{array}$ & $\begin{array}{l}0.27^{\star \star *} \\
0.19^{\star \star \star}\end{array}$ & $\begin{array}{l}0.74^{* * *} \\
0.76^{* * *}\end{array}$ & $\begin{array}{l}0.81^{\star * *} \\
0.79^{\star * *}\end{array}$ & $\begin{array}{l}0.80^{\star \star *} \\
0.82^{\star \star \star}\end{array}$ & $\begin{array}{l}-0.13^{\star \star \star} \\
-0.19^{\star \star \star}\end{array}$ & & $\begin{array}{l}0.29^{\star \star \star} \\
0.30^{\star \star \star}\end{array}$ \\
\hline $\begin{array}{l}\text { Figure } 8 \\
\text { test }\end{array}$ & $\begin{array}{l}2003 \\
2010\end{array}$ & $\begin{array}{l}0.44^{* * *} \\
0.44^{\star * *}\end{array}$ & $\begin{array}{l}0.21^{\star * *} \\
0.19^{\star \star \star}\end{array}$ & $\begin{array}{l}0.42^{* * *} \\
0.48^{\star * *}\end{array}$ & $\begin{array}{l}0.47^{* * *} \\
0.51^{* * *}\end{array}$ & & $\begin{array}{l}-0.07^{\star} \\
-0.13^{\star \star}\end{array}$ & $\begin{array}{l}0.76^{\star \star \star} \\
0.76^{\star \star \star}\end{array}$ & $\begin{array}{l}0.22^{\star \star} \\
0.19^{\star \star \star}\end{array}$ \\
\hline Lateral jump & $\begin{array}{l}2003 \\
2010\end{array}$ & $\begin{array}{l}0.29^{\star \star *} \\
0.37^{\star \star \star}\end{array}$ & $\begin{array}{l}0.21^{\star \star \star} \\
0.14^{\star \star \star}\end{array}$ & $\begin{array}{l}0.45^{\star * *} \\
0.42^{\star * *}\end{array}$ & & $\begin{array}{l}0.37^{\star \star \star} \\
0.42^{\star \star \star}\end{array}$ & $\begin{array}{l}-0.14^{\star \star \star} \\
-0.14^{\star \star \star}\end{array}$ & $\begin{array}{l}0.79^{\star \star \star} \\
0.78^{\star \star \star}\end{array}$ & $\begin{array}{l}0.20^{\star \star} \\
0.26^{\star \star \star}\end{array}$ \\
\hline $\begin{array}{l}\text { Participation } \\
\text { organized } \\
\text { PA }\end{array}$ & $\begin{array}{l}2003 \\
2010\end{array}$ & & $\begin{array}{c}0.08^{\star} \\
0.07 \text { (ns.) }\end{array}$ & $\begin{array}{l}0.27^{\star \star \star} \\
0.32^{\star \star \star}\end{array}$ & $\begin{array}{l}0.23^{\star \star \star} \\
0.32^{\star \star \star}\end{array}$ & $\begin{array}{l}0.26^{\star \star \star} \\
0.21^{\star \star \star}\end{array}$ & $\begin{array}{c}-0.01 \text { (ns.) } \\
-0.10^{\star \star}\end{array}$ & $\begin{array}{l}0.31^{\star \star \star} \\
0.35^{\star \star \star}\end{array}$ & $\begin{array}{l}0.77^{\star \star \star} \\
0.79^{\star \star \star}\end{array}$ \\
\hline
\end{tabular}

Note: Correlation at level ${ }^{* *} p<0.001,{ }^{* *} p<0.01,{ }^{*} p<0.05, n s$. nonsignificant correlation

\section{Note: coefficients for girls bolded}

This article is protected by copyright. All rights reserved. 
Table 4. Main and interaction effects for the influence of FMS and PA on BMI adjusted by province and the municipality.

\begin{tabular}{|c|c|c|c|c|c|c|}
\hline & & Bo) & $(n=1760)$ & & Girls ( & 1758) \\
\hline & $d f$ & $F$ & $p$ & $d f$ & $F$ & $p$ \\
\hline FMS & 2 & 44.87 & $<0.001$ & 2 & 33.11 & $<0.001$ \\
\hline PA & 2 & 1.02 & 0.389 & 2 & 0.19 & 0.831 \\
\hline $\mathrm{FMS}$ * PA & 4 & 0.40 & 0.804 & 4 & 1.46 & 0.279 \\
\hline & $R^{2}=$ & $47=4$ & & $R^{2}=$ & $.047=$ & $7 \%$ \\
\hline
\end{tabular}

This article is protected by copyright. All rights reserved. 